\title{
Recanalization method for pancreatic duct stricture complicated by a huge pancreatic stone
}
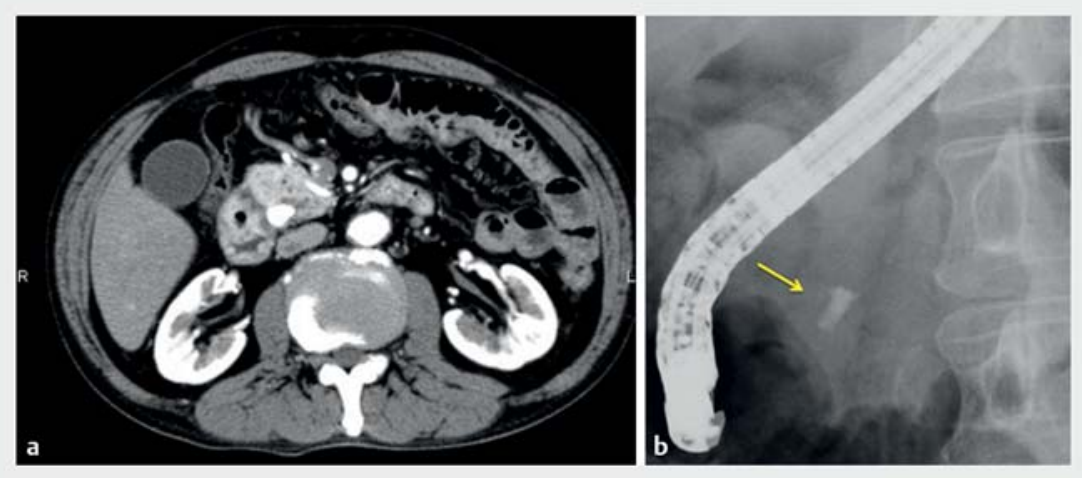

- Fig. 1 A huge pancreatic duct stone (arrow) was seen in the pancreatic head. a Computed tomography. b Fluoroscopic imaging.

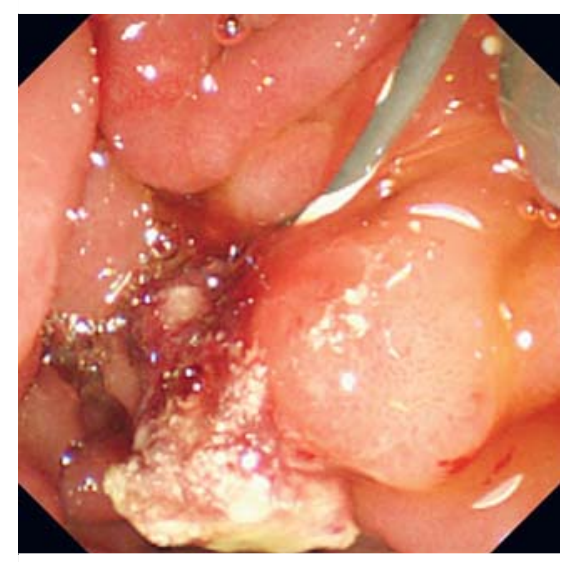

- Fig. 3 Fragmentation of the pancreatic duct stone was achieved by insertion of the Soehendra stent retriever.

Chronic pancreatitis is sometimes complicated by both pancreatic stones and pancreatic duct stricture [1-3]. In such situations, stone fragmentation may be needed before a stent can be placed. Electrohydraulic lithotripsy is one of the treatment methods used to achieve stone fragmentation. However, if the pancreatic stone is located in the pancreatic head, pancreatoscope insertion is sometimes challenging. We describe herein technical tips for a recanalization method for pancreatic duct stricture

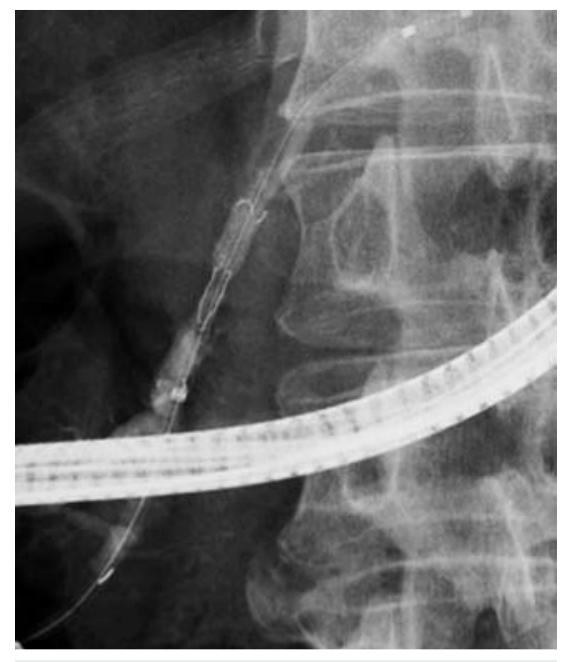

- Fig. 4 Deployment of a covered metal stent was successfully performed.

complicated by a huge pancreatic duct stone.

A 68-year-old man was admitted to our hospital with abdominal pain caused by chronic pancreatitis. On computed tomography, a huge pancreatic duct stone was seen in the pancreatic head ( $\triangleright$ Fig.1a). Placement of a pancreatic duct stent was attempted under endoscopic retrograde cholangiopancreatography (ERCP) guidance.

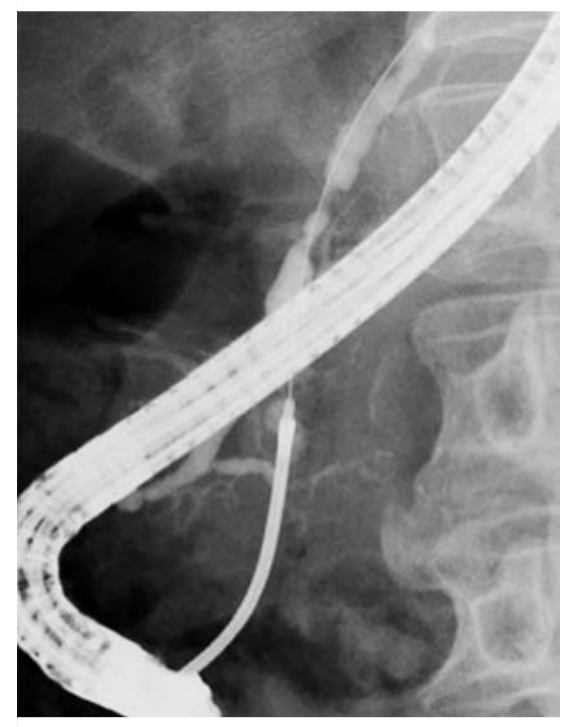

- Fig. 2 A Soehendra stent retriever was inserted to dilate the pancreatic duct.

First, the duodenoscope was advanced into the ampulla of Vater. The huge pancreatic duct stone was seen in the pancreatic head ( $>$ Fig. 1 b). The ERCP catheter (MTW Endoskopie, Düsseldorf, Germany) was inserted into the pancreatic duct, and a guidewire (VisiGlide; Olympus Medical Systems, Tokyo, Japan) was placed. On cholangiographic imaging, the pancreatic duct stricture was seen in the pancreatic body. As none of the devices could be advanced into the pancreatic body, a Soehendra stent retriever (SSR-7; Cook, Tokyo, Japan) was used and was successfully inserted into the pancreatic body ( $\triangleright$ Fig. 2, $\triangleright$ Video 1 ). Insertion of the Soehendra stent retriever dilated the stricture and partial stone fragmentation was achieved (> Fig. 3 ). Then, a covered metal stent (BONASTENT M-Intraductal Standard; Sci-Tech Inc., Seoul, South Korea) was deployed within the pancreatic body duct ( $>$ Fig. 4). Finally, a plastic stent (Type IT; Gadelius Medical Co., Ltd., Tokyo, Japan) was deployed from the pancreatic tail to the duodenum, without any adverse events. 


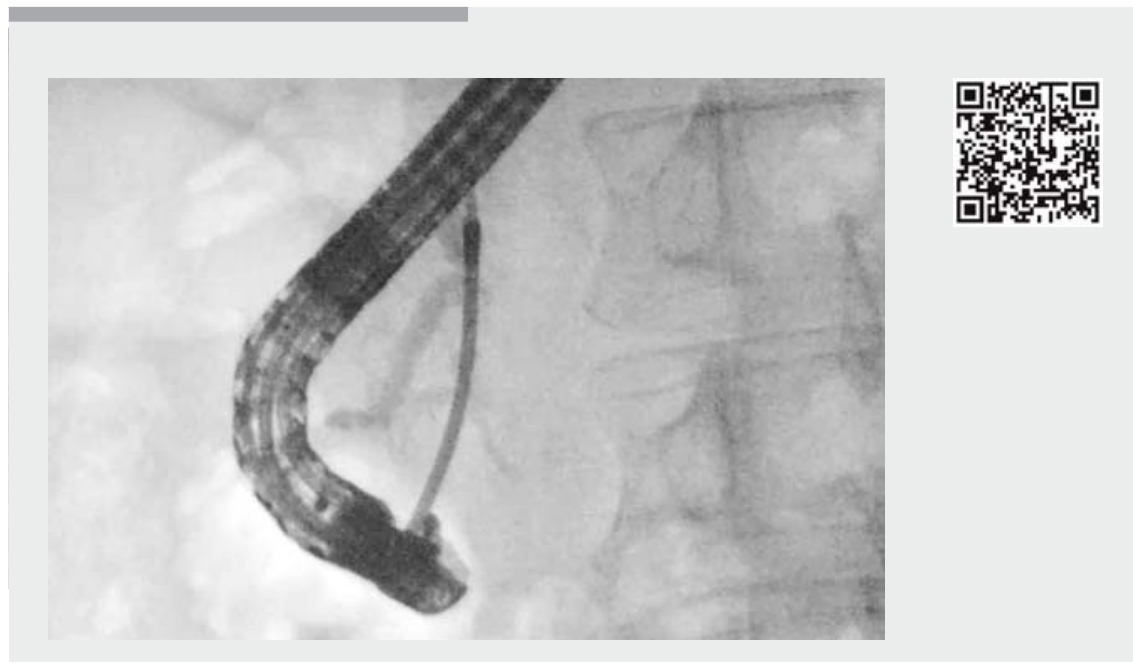

$\checkmark$ Video 1 Recanalization of the pancreatic duct using a Soehendra stent retriever.

The patient was discharged because symptoms improved. Our technique may be an option for the treatment of huge pancreatic duct stones.

Endoscopy_UCTN_Code_TTT_1AR_2AI

\section{Competing interests}

None

Takeshi Ogura, Rieko Kamiyama, Masanori Yamada, Shinya Fukunishi, Kazuhide Higuchi 2nd Department of Internal Medicine, Osaka Medical College, Osaka, Japan

\section{Corresponding author}

\section{Takeshi Ogura, MD}

\section{References}

[1] Devière J. Pancreatic stents. Gastrointest Endosc Clin N Am 2011; 21: 499-510

[2] DiMagno EP, DiMagno MJ. Chronic pancreatitis: landmark papers, management decisions, and future. Pancreas 2016; 45: 641 650

[3] Yan LH, Li L, Chen JS. Chronic pancreatitis. Curr Opin Gastroenterol 2017; 33: 396-403

\section{Bibliography}

DOI https://doi.org/10.1055/a-0631-8641

Published online: 19.6.2018

Endoscopy 2018; 50: E250-E251

(c) Georg Thieme Verlag KG

Stuttgart · New York

ISSN 0013-726X

\section{ENDOSCOPY E-VIDEOS}

https://eref.thieme.de/e-videos

2nd Department of Internal Medicine, Osaka Medical College, 2-7 Daigakuchou,

Takatsukishi, Osaka 569-8686, Japan Fax: +81-726846532

oguratakeshi0411@yahoo.co.jp 